\title{
Why not apply an engineering methodology when creating courses?
}

\author{
Sylvie Doré, Josianne Basque \\ École de technologie supérieure/Télé-université \\ Montréal, Québec, Canada
}

\section{Introduction}

Much too often, we rely on lectures to teach our students. In times when books were rare and prohibitively expensive, professors in schools and universities would "faire la lecture" or read out loud books at their disposal. In the meantime, under dictation, students would copy the contents of the books on whatever writing material they had at their disposal. At the time, it made sense to lecture, as a basic requirement for learning is having access to the knowledge and it was the only way to do so. Since those days, not only has printing technology evolved, but new media have emerged; understanding of cognitive processes has progressed, learning theories have been developed and tested, new methods and tools have been created. Yet, practices used in most of our engineering faculties and schools do not reflect this wealth of knowledge.

One of these practices concerns the way we go about creating a new course or even a new curriculum. This paper presents the concept of instructional engineering (IE), in emergence for the last 40 years in the field of education. The two following sections will attempt to answer the following questions: What is IE? Why use IE? Finally, the last section will quickly present one IE method, namely MISA (a French acronym for Method for engineering learning systems).

\section{What is instructional engineering?}

Simply stated, instructional engineering is a systematic, systemic and heuristic process by which one produces a learning system. Let us first start by examining this process by drawing a parallel with the process used by engineers to create artifacts or products. We will then move on to clarify the concept of learning system.

For quite some time, professional engineers have been formalizing the method by which they create products. This has given rise to a large number of design and engineering models. Design is generally considered as an activity by which one generates a set of specifications in order to make a product which will satisfy a given set of requirements and constraints. A design model represents a specific method used to carry out this task. We consider design as a subset of the engineering method in the sense that engineering covers the whole life cycle of a product, starting with the analysis of customer needs, specifications and constraints, moving on to design, production, distribution, maintenance and even recycling. 
In recent years, one hears more and more often of product development or product engineering as opposed to product design. This change of vocabulary reflects the basic concurrent engineering principle that consideration should be given to downstream activities, such as assembly, manufacturing, maintenance, etc. while designing the product, or in other words, to consider the whole life cycle of the product right from the start of the project and during all the design phase.

The term "product" is taken here in its broadest sense, as suggested by Floyd et al. ${ }^{\mathbf{1}}$ It refers to hardware (a chair, a television set, an airplane), to software (word processor, authoring software), to a service (banking, restoration), to a process (pasteurization of milk, metal sheet bending) or a combination of the above. The engineering method is generic as it is applied in all fields where one has to image a solution that will satisfy the needs of potential customers, whether those needs be educational, financial, medical, industrial, etc.

This generic aspect probably originates from the fact that the engineering method reflects the problem solving method based on the systemic approach proposed by the general systems theory. While the description of this approach varies slightly from author to author, its generally consists of defining and analyzing the problem, of designing a solution, implementing this solution and finally controlling or evaluating it. Romizowski ${ }^{\mathbf{2 , 3}}(1992,1996)$ observes that this approach is more heuristic in nature than it is algorithmic.

Prompted by the desire to guide educators in creating more efficient learning systems (such as activities, lessons, courses, or whole curriculum), researchers from the field of education started developing their own design models. The expression instructional design thus appeared in the 1960's. In recent years, instructional design is more and more often equated with instructional or cognitive engineering ${ }^{\mathbf{4 , 5 , 6}}$, reflecting the change of vocabulary already noted.

Let us now take a closer look at the expression learning system.

The use of the term learning instead of the term teaching reflects a change of paradigm from teaching to learning ${ }^{\mathbf{7 , 8 , 9}}$. The emphasis is shifted from what an instructor has to teach (from the lecture), to the activities students should perform in order for them to learn.

In a general sense, a system designates a set of components oriented by a common goal, which, under the influence of a stimulus, generates a response. The concept of feedback is evoked as a means of regulating this response. Furthermore, systems are generally represented in an environment. When applied to the educational context, the word system highlights the fact that for learning to take place, a certain number of components (learner, instructor, learning material, etc.) are in interaction and pursue a common goal (learning), emphasizing the need for coherence. Furthermore, feedback must be designed within the system to generate the desired outcome, i.e. for the students to achieve learning objectives (either self or instructor-defined). Finally, this learning system is necessarily influenced by the environment (administrative, technological, pedagogical, etc., macro-systems) in which it is implemented.

It should therefore not come as a surprise if most instructional design (or engineering) models ${ }^{10,11,12,13}$ are similar to the generally recognized phases of the engineering method used to create industrial products, both reflecting the systemic approach. When applied to educational 
products, these phases are generally defined as: analysis, design, production, validation and delivery. These phases are not necessarily sequential and generally integrate one or several feedback loops.

Analysis During this phase, one proceeds to describe the target learners, their actual level of knowledge and the desired outcome; the available human, financial and material resources; the anticipated costs vs benefits, etc. This is comparable to describing system output, as well as the environment in which the system will be developed and implemented.

Design This phase aims at choosing a pedagogical approach (behaviorism, cognitivism, constructivism, humanism, etc.), pedagogical strategies (project, simulation, role playing, problem solving, case study, collaborative work, etc.) and media (paper based or electronic web-based documentation, hypermedia, etc.); at formulating learning objectives; at defining the learning objects or subject matter; at creating and improving the learning and teaching scenarios; at generating the specifications for the educational material. This amounts to designing the system components.

When the learning systems are particularly complex, this phase can be broken down into sub-phases during which the different components are refined: preliminary, architecture and detailed design.

Production In this phase, the learning system is actually created according to the specifications defined in the previous step. Class notes or books are written, simulations are coded, videos are produced, web sites programmed, etc.

Validation The goal of this phase is to test the learning system with a limited number of representative target learners, to gather data in order to bring corrections or improve the learning system prior to full scale delivery. This is clearly a means of providing feed-back to the process. It is similar to testing a beta version of an industrial product.

Delivery This phase consists in making the learning system available, sometimes requiring an organizational and technological infrastructure. This also includes the maintenance of the system.

\section{Why use instructional engineering?}

We can evoke at least four good reasons to use an instructional engineering method.

Efficiency Instructional engineering strives to provide one with the means of producing more efficient, more pertinent, more coherent and more innovative learning systems. By more efficient, we mean that more students will achieve the learning objectives; pertinence relates to the type of tasks learners will accomplish once in the workplace; coherence is required to reach a common 
goal; innovation applies to the choice of a preferred learning theory, to the media, to teaching and learning strategies, etc. and can be an important motivational factor for the learners.

Complexity Several factors contribute to increase the complexity of the modern learning systems.

- We have already evoked the paradigm shift from teaching to learning. When one recognizes that most of the learning is achieved outside the classroom, and that attending a lecture is one of the least effective learning strategies, one strives to design better teaching/learning scenarios making use of various strategies. One also tries to prepare activities for students to perform outside the classroom with the same care as one prepares in-class activities.

- This is even more important when one tries to encourage deep learning and strategic learning as opposed to shallow learning ${ }^{\mathbf{1 4 , 1 5 , 1 6}}$. One must then: make sure that the learners can relate new knowledge to their own knowledge base; clearly state the learning objectives or make the learners define objectives for themselves; establish pertinence with related material within the learning system, with other courses, with the professional practice; avoid stressful situations by planning for a proper workload, by encouraging cooperation rather than competition; offer choices such as bonus activities, the possibility of improving material handed-in for evaluation, different subjects for projects; vary teaching style in order to match a wider range of learning styles, etc.

- Another source of complexity is the exponential growth of knowledge, as well as the increasing demand from society to better educate our students as all round citizens, compelling one to make important choices.

- Finally, the advent of the information and communication technologies and the push to introduce these new technologies in existing and new learning systems also increase complexity. It is even greater when the learning system is to be used for distance learning. The margin for improvisation and last minute adjustments is then greatly reduced.

Instructional engineering methods offer an inventory of the different decisions one must continuously make when creating a new learning system. By representing this decision making process in a structured form, through schematics and in written form, the method guides one through the process. In short, it helps one manage complexity, provide coherence and discipline the evolution of the system.

Communication Just as the use of concurrent engineering makes use of multidisciplinary teams, the creation of learning systems of a certain complexity requires the collaboration of a number of professionals, often coming from different disciplines: content experts, instructional engineers, multimedia producers, programmers, to name a few. Communication problems are common in these situations. Each come to the drawing table with their own theoretical and 
methodological scheme of reference, specialized vocabulary, etc. Andrew and Goodson ${ }^{10}$ contend that the use of an instructional engineering method is a useful communication tool. The adoption of an explicit and recognized method leads to the adoption of a common vocabulary and methodology. It also becomes easier to distribute roles and responsibilities. Each member can refer to the method to understand the relationship between one's work and that of other team members. Finally, the documents produced can more easily be shared and discussed by all.

Cost The use of instructional design usually leads to lower costs and to effectiveness reduction of development time as well as it diminishes the risk of making costly errors.

\section{MISA: Method for Engineering Learning Systems}

Over the years, both authors have made use of MISA ${ }^{6}$, the Method for engineering learning systems developed at the Télé-université research center LICEF (French acronym for Laboratory for Cognitive Informatics and Training Environments). It is schematically described in figure 1.

It is one of the few methods which relies on an approach very similar to concurrent engineering. The method is broken down into six phases roughly corresponding to different steps in the generic engineering process:

- project definition

- analysis and preliminary design (or problem definition and conceptual or preliminary design)

- architecture design (or macro-design)

- design of instructional material (or micro-design or detailed design)

- production and validation of instructional material

- implementation (or delivery and maintenance.)

Within each phase, four different axes are developed in parallel, each represented by a model:

- knowledge or subject matter model

- instructional or pedagogical model

- media model

- delivery model.

The different models are created with a computerized knowledge modeling tool called MOT (French acronym for Object-Oriented Modeling). Readers should note that the use of an objectoriented methodology and tools does not necessarily lead to an object-oriented or agent-based learning environment. Examples of such environments include the efforts of the Greenfield Coalition $^{17}$ and of Norrie and Gaines ${ }^{\mathbf{1 8}}$.

An example of a knowledge model is shown in figure 2. It is a first-level representation of a procedural knowledge, that is the procedure of developing a pedagogical model. For lisibility, many knowledge objects of this model are not shown. 
Session 2230

\begin{tabular}{|c|c|c|c|c|}
\hline Project definition & $\begin{array}{c}\text { Analysis/ } \\
\text { Preliminary desi }\end{array}$ & Architecture design & $\begin{array}{c}\text { Instructional mat } \\
\text { design }\end{array}$ & $\begin{array}{c}\text { Production/ } \\
\text { Validation }\end{array}$ \\
\hline
\end{tabular}

Knowledge

Pedagog

Media

\section{Delivery}

Figure 1 Representation of the MISA method

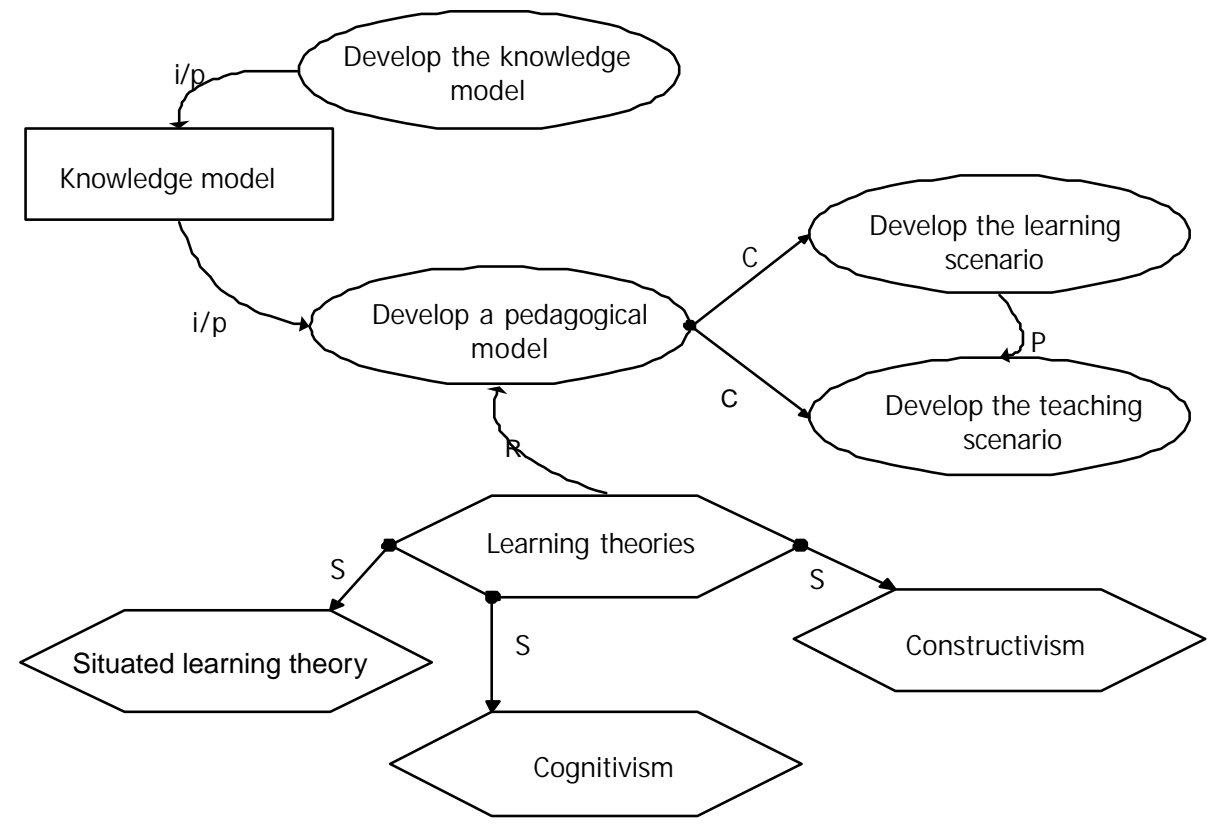

Figure 2 Example of a knowledge model

Without going into too much detail, let us say that different types of knowledge are depicted by different shapes: rectangles denote concepts (what?); ellipses are used to represent procedures (how?); principles (why, when, if...then) are shown as six-sided parallelograms. Other shapes, not shown in figure 2, are used to illustrate facts. Links between knowledge objects are also typed. For example, "C" denotes composition; "R" stands for regulation; "I/P" signifies input/product; " $\mathrm{S}$ ” denotes specialization, or "sort of"; "P" implies precedence. MOT allows for other types of links, not shown in figure 2. 
The content of figure 2 can be interpreted as follows. The procedure described in the pedagogical axis is composed of two sub-procedures leading to the generation of learning and teaching scenarios (in distance education, we would speak of tutoring scenarios). The elaboration of the learning scenario should precede that of the teaching scenario. The knowledge model, a product of applying the procedure described by the knowledge axis, is used as input to the pedagogical axis procedure. Finally, the different choices will be conditioned or regulated by learning theories, three of which are illustrated as "sort of" theories.

Object-oriented modeling can be used to develop the all four models of MISA. Apart from easing communication, the greatest advantage of this technique is ensuring a greater coherence between the different knowledge objects and the teaching/learning strategies selected for their appropriation by the learners. Furthermore, the separation of knowledge and pedagogical models makes it possible to easily create different learning and teaching scenarios for the same knowledge model, thereby explicitly taking into account different learner populations.

Both authors have been using MISA to develop different sorts of learning systems ranging from distance learning environments (www.teluq.uquebec.ca/producmm and http://www.teluq.uquebec.ca/tec6312), to a web-based study program environment to support student motivation, perseverance and success as well as to in-class courses.

We have personally experienced the benefits promised by the use of this instructional engineering method. To illustrate this point, we briefly present an online course on which both authors collaborated. This course is a 6 credit ( 270 hours, spreaded out over two semesters), graduate course on Instructional Engineering of Computerized Learning Environments. Students are invited to perform six learning activities, three of which are devoted to a self-chosen project of designing a learning system. The three other activities include (1) exploration of the course environment and material and meeting other virtual students; (2) reading theoretical texts on instructional design and on the proposed design methodology (MISA) and (3) doing a critical analysis of the MISA method.

The students have access to the course material through an interactive multimedia interface, illustrated in figure 3. This portion of the learning system is downloaded on the student's computer to avoid costly and lengthy online sessions. Looking as a game board, the interface highlights the learning scenario in the central section. Through this interface, students have access to:

- 13 original texts exposing theoretical concepts

- 15 texts detailing the procedures of the MISA method

- 20 forms

- 4 methodological guides

- a full example composed of 15 documents and 7 models

- an interactive study time management tool

- an interactive lexicon

- the software MOT

- a complementary web site. 
The web site (http://www.teluq.uquebec.ca/tec6312), based on the metaphor of a professional association of instructional designers web site, is dedicated to communication with peers and tutor through structured text-based teleconferences, exhibition of the students productions, downloading of material, etc. In short, the web site is used mostly for communication purposes, while the locally installed portion of the learning system contains all the material (information) necessary to perform the learning activities.

The material is completed by a CD containing interviews and a manual of the MISA method.

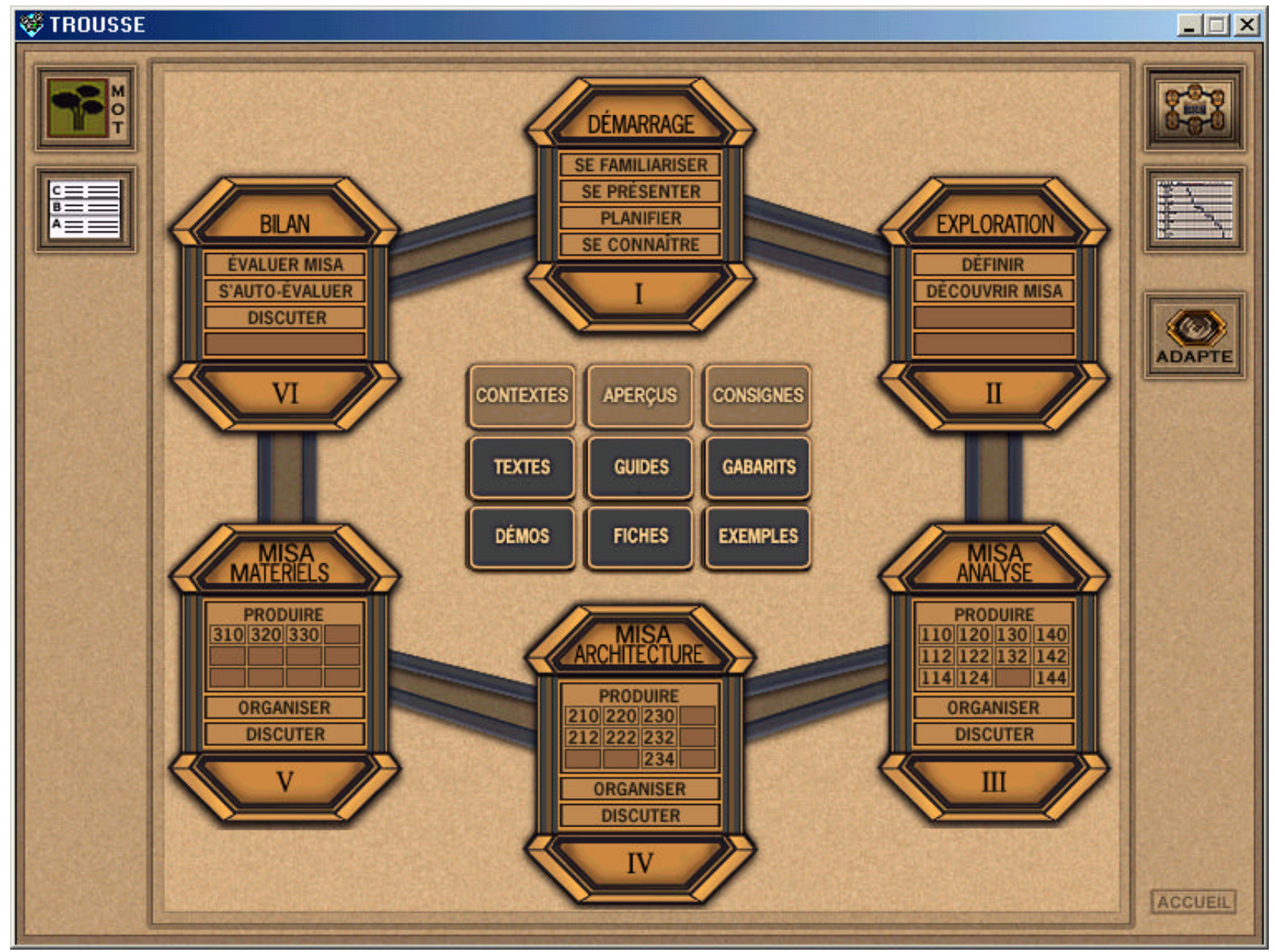

Figure 3 Multimedia interactive interface developed for the Instructional design online course

The use of an instructional engineering method proved particularly useful in managing the complexity of the learning system. We built an innovative learning environment where students achieve learning objectives through meaningful activities. Only minor changes, representing less than one person-week of work, where required after the first delivery, a testimony of cost effectiveness. The course has now been running for over 3 years without any problems.

Our efforts were crowned in 2000 by the Excellence in Learner-centered IT award granted by the Canadian Association for Distance Education (CADE). The pedagogical scenario, which 
describes all the tasks the learner must perform, as well as the material and tools required as input to these tasks along with the output produced by the learner, was especially helpful in remaining learner centered rather content focused. It was an extremely useful tool in bringing about the paradigm shift from teaching to learning.

\section{Conclusion}

As professors, teachers and instructors in engineering faculties, we would not dream of letting our graduates leave our walls without minimal knowledge of design or engineering methodology and of the tools used to carry out this methodology. The more so as products become more complex and as a reduced lead-time and economic considerations put added pressure on development teams.

Entrusted with the responsibility of educating these young people, do we not have the obligation of using state of the art tools, methodologies and knowledge to create the best learning systems we can? Will we have the courage to practice what we teach?

\section{References}

1. Floyd, T.D., Levy, S. et Wolfman, A.B. (1993). Winning the Product Development Battle. IEEE Engineers Guide to Business series, B. Coburn, ed. New York: The Institute of Electricaland Electronics Engineers Inc.

2. Romiszowski, A. J. (1992). Designing instructional systems. Decision making in course planning and curriculum design. London/New York : Kogan Page/Nichols Publishing.

3. Romiszowski, A. J. (1996). Systems approach to design and development. In T. Plomp and D. P. Ely (Eds.), International Encyclopedia of Educational Technology (pp. 37-43). Cambridge, UK : Pergamon.

4. Di Vesta, F.J. and Rieber, L.P. (1987). Characteristics of cognitive engineering: The next generation of instructional systems. Educational Communications and Technology Journal, 35(4), 213-230.

5. Stolovitch, H. Keeps, E. J. (1993). L’ingénierie de la formation. Montréal: Harold D. Stolovitch et Erica J. Keeps.

6. Paquette, G., Crevier, F., and Aubin, C. (1999). MISA, A knowledge-based Method for the Engineering of Learning Systems, Journal of Courseware Engineering, vol. 2.

7. Barr, R. B. and Tagg, J. (1995) From Teaching to Learning - A New Paradigm for undergraduate Education. Change, November/December, 13-25.

8. Flynn, William J. (2000). The Search for the Learning-Centered College. New Expeditions: Charting the Second Century of Community Colleges. Issues Paper No. 9. Community College Press, P.O. Box 311, Annapolis Junction, MD 20701-0311. http://www.aacc.nchc.edu/newexpeditions/White_Paper/ learningwhite.htm.

9. Wilson, B. G. (1995). Metaphors for instruction: Why we talk about learning environments. Educational Technology, 35(5), 25-30.

10.Andrews, D., et Goodson, L. (1991). A comparative analysis of models of instructional design. In G. J. Anglin (Ed.), Instructional technology : Past, present and future (pp. 133-155). Enlewood, Colorado : Libraries Unlimited.

11. Gustafson, K. L. (1996). Instructional design models. In T. Plomp et D. P. Ely (Eds.), International Encyclopedia of Educational Technology (pp. 27-32). Cambridge, UK : Pergamon.

12. Visscher-Voerman, J. I. A., et Plomp, T. (1996). Design approaches in training and education. In T. Plomp et D. P. Ely (Eds.), International Encyclopedia of Educational Technology (pp. 22-26). Cambridge, UK : Pergamon.

13. Wiggins G. and McTighe, J. (1998). Understanding by design. Association for Supervision and Curriculum Development, Alexandria, Va.

14. Jonassen, D. H. (1988). Integrating learning strategies into courseware to facilitate deeper processing. In D. H. Jonassen, Instructional designs for microcomputer courseware (pp. 151-181). Hillsdale, NJ: Erlbaum. 
15. Sandberg, J., Barnard, Y. (1997). Deep Learning Is Difficult. Instructional Science; v25, no. 1, 15-36.

16.Chin, Christine; Brown, David E.(2000). Learning in Science: A Comparison of Deep and Surface Approaches. Journal of Research in Science Teaching; v37, no. 2, 109-38..

17. Falkenburg, D. (2001). E-learning in the Greenfield Coalition. International Conference on Engineering Education, Oslo, August 6-10, 6E2-11. http://fie.engrng.pitt.edu/icee/papers/558.pdf

18. Norrie, D. H. and Gaines, B. R. The learning Web: A system view and an Agent-Oriented Model. http://ksi.cpsc.ucalgary.ca/articles/LearnWeb/EM95J/

\section{Biography}

Dr. Sylvie DORÉ is a full professor in the mechanical engineering department at École de technologie supérieure (ETS) where she teaches courses in product development, applied numerical methods and rapid prototyping. She co-developed two web-based distance learning courses, one on the use of multimedia for educational purposes and the other on instructional design. She was awarded the ETS best teacher award in 1999.

sylvie.dore@etsmtl.ca

Dr. Josianne BASQUE, Ph.D. in Psychology, is Associate professor at Télé-université, a distance learning open university, where she develops online courses in the field of educational technology. She worked as a professional in this field for more than twelve years before becoming professor. Her research interests are instructional engineering, distance learning environments, collaborative learning and metacognition. For more information: www.teluq.uquebec.ca/spersonnel/jbasque.

jbasque@teluq.uquebec.ca 